\title{
Wood anatomical changes in roots of European ash (Fraxinus excelsior L.) after exposure
}

\author{
O.M. Hitz ${ }^{\mathrm{a}, *}$, H. Gärtner ${ }^{\mathrm{b}}$, I. Heinrich ${ }^{\mathrm{a}}$, M. Monbaron ${ }^{\mathrm{a}}$ \\ ${ }^{a}$ Department of Geosciences, Geography, University of Fribourg, Chemin du Musée 4, 1700 Fribourg, Switzerland \\ ${ }^{\mathrm{b}}$ Swiss Federal Institute for Forest, Snow and Landscape Research WSL, Zürcherstrasse 111, 8903 Birmensdorf, Switzerland
}

\begin{abstract}
Global changes have distinct influence on fluvial processes in torrents causing erosion on slopes and riverbanks even in forested areas. Continuous as well as discontinuous erosion of riverbanks covered by trees frequently results in destabilisation and finally cause the trees affected to tip over. These uprooted trees may lead to a blockage of the river and, in the case of a collapse of the resulting dam, resulting in severe flooding or even debris-flow surges. Dating the time of root exposure along riverbanks allows the reconstruction of erosion dynamics. In the previous studies, roots of coniferous trees have shown anatomical changes (cell size reduction in earlywood) after exposure. This anatomical feature in the xylem of exposed roots has helped to determine the time of exposure at an annual resolution. In the current study, this methodology is now applied for the first time to European ash (Fraxinus excelsior L.) to determine its specific reactions to root exposure.

First results show different reactions in vessel and fibre dimensions. Fibres show a distinct decrease in lumen area due to exposure, whereas vessel lumen area displays more variability ranging from $50 \%$ size reduction to no changes. It is discussed that vessel size characteristics are also related to ecophysiological and climatic patterns.
\end{abstract}

Keywords: Dendrogeomorphology; Root exposure; River erosion; Ash tree; Fraxinus excelsior L.; Wood anatomy

\section{Introduction}

Alpine areas are highly affected by various geomorphic processes such as landslides or debris flows. Most of these processes can cause severe damage to existing infrastructure in the affected areas. Due to the effects of global change (IPCC, 2001), the potential risk of natural hazards occurring in alpine areas is expected to increase to an even higher risk level than it has been recorded for the last century (PLANAT, 2005). These

\footnotetext{
*Corresponding author. Tel.: + 41263009250 ; fax: +41263009746 .

E-mail address: oliver.hitz2@unifr.ch (O.M. Hitz).
}

global changes are also likely to have distinct influences on fluvial processes in torrents causing more erosion on slopes and riverbanks even in forested areas.

Protective actions by forestry authorities in forests along alpine torrents have so far mostly concentrated on cutting down bigger trees growing along the riverbanks of torrents to lower the risk of uprooting due to erosional events (Wasser and Frehner, 1996; Schumm, 2003). These actions also aim to reduce the risk of deadwood and potential blockages within the torrents, which ultimately might cause catastrophic flood waves in the case of a bursting dam. However, sparse knowledge exists about the effects of these forest management actions on the drainage zones of mountain torrents and 
the potential of the torrents to become a hazard. As the forest actions are very cost-intensive, it is important to know if they are necessary and efficient. New tools need to be developed to estimate more precisely the risk potential of threatened regions in order to supply politicians and foresters with more data and thus facilitate suitable forest management.

Dating the time of root exposure along riverbanks allows the reconstruction of erosion dynamics also leading to a potential destabilisation of trees on the riverbanks. Fayle (1968) conducted experiments on exposure and burying of roots of Pinus sylvestris L. and Pinus banksiana Lamb. He showed that in the exposed part of a root compared to its buried parts ring width increased after exposure. The increase was not limited strictly to the exposed portion but usually extended approximately half a metre in both directions from the exposed surface. In addition, the tangential and radial diameters of tracheids were reduced due to exposure (Fayle, 1968). Morneau and Payette (1998) analysed root scars and anatomical changes in the wood structure of exposed roots to reconstruct passages of caribous. Exposed roots adopted the anatomical structure of stem wood during the same season the exposure occurred, and this change from root-like to stem-like wood was identifiable in low magnification with a binocular microscope. Gärtner (2003) noted that roots of Larix decidua Mill. and other coniferous trees react on exposure with a decreasing cell lumen in the earlywood portion of an annual ring. A threshold value of $50 \%$ below the tracheid lumen area of the previous years was identified as the wood anatomical signal for root exposure. Changes in latewood to a stem-like structure already appear before exposure of the root as a reaction of a lowering soil surface (Gärtner et al., 2001; Gärtner, 2007).

No studies have been conducted yet focusing on the wood anatomical reactions of ash roots due to exposure. Hence, the current study aims to identify the wood anatomical response of European ash (Fraxinus excelsior L.) due to exposure.

\section{Materials and methods}

The sites selected for our study were mountain torrents showing exposed roots of both coniferous and ash trees ( $F$. excelsior L.) obviously influenced by erosional processes along the riverbanks. The anatomical reactions due to exposure are already known for conifers (Gärtner et al., 2001) and hence act as a reference during the analysis of the ash roots. Disc samples were taken from the roots and their respective positions were marked in the documented profiles. At each position two discs were sampled, one for macroscopical analysis of ring-width variations and the second for preparing micro-slides to analyse anatomical variations.

The surfaces of all discs were treated with a belt sander (400 grain) to prepare for general macroscopic analysis and to define the positions most suitable for preparing micro-sections used for wood anatomical analysis (Fig. 1). Altogether 36 pairs of discs were analysed. Micro-sections were cut with a sledge microtome at a thickness of approximately $15 \mu \mathrm{m}$, stained with Safranine and Astra blue and fixed in Canada balsam (Schweingruber, 1978). Finally, digital photos of the microscope slides were taken for further digital image analysis.

Tracheid features of the coniferous roots (tracheid lumen size, tracheid wall thickness) were measured with the automatic image analysis software WinCELL. The system allows automatic object recognition. Cell lumen areas are delimited based on a threshold grey level, which was adjusted for each sample. Earlywood tracheids of coniferous roots were measured in radial direction to analyse cell lumen length and cell wall thickness. An area of about $0.5 \mathrm{~mm}^{2}$ of each annual ring of the sample was analysed. A size filter was applied after object recognition. The minimum value of the size filter was set at $300 \mu \mathrm{m}^{2}$ because this proved to be the minimum size of a tracheid. Objects smaller than this value were normally lumina of tracheids near their ends in longitudinal direction and hence not representative. No maximum filter was applied. Mean values of the various cell dimensions were calculated for each tree ring visible in the micro-sections.

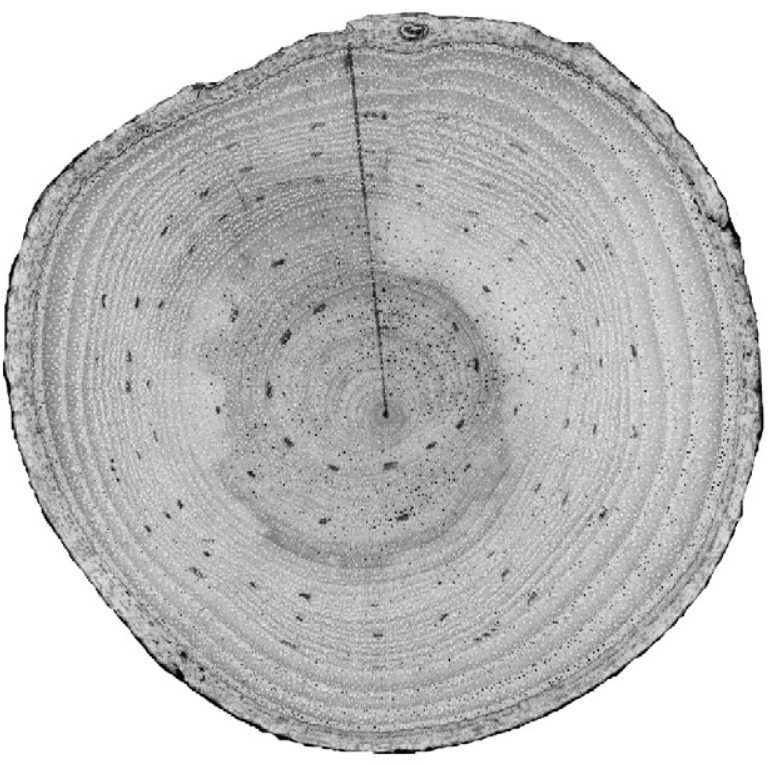

Fig. 1. Sanded cross-section of a root from European ash. The line indicates the location of the micro-section shown in Fig. 5. The points indicate individual growth layers, each fifth year is marked. 

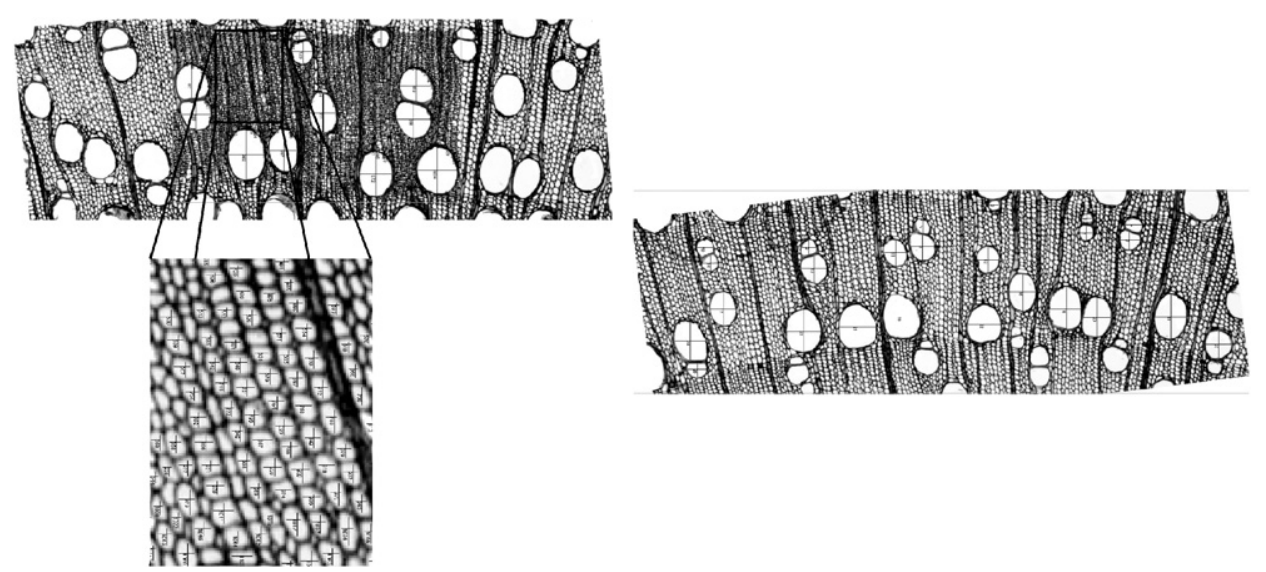

Fig. 2. Micro-section taken from a root of European ash showing fibre (left image) and vessel (right image) measurements by WinCELL.

The analysis of ash roots concentrated on possible variations in the anatomical structure of vessels and fibre cells as well as on differences in earlywood and latewood. The measuring procedures for ash roots were comparable to those applied to coniferous roots, but it was necessary to adapt them to the general anatomy of ash.

For the fibre measurements sectors of about $1 \mathrm{~mm}^{2}$ including one full tree ring were selected (Fig. 2, left image). The threshold for defining an element as a fibre and to differentiate it from a vessel was set at $800 \mu \mathrm{m}^{2}$ (corresponding to a lumen diameter of $16 \mu \mathrm{m}$ ) and thus smaller elements were classified as fibres. Elements smaller than $40 \mu \mathrm{m}^{2}$ were not measured. This decision is based on a large number of cell areas examined microscopically. In the defined sectors the lumen areas of approximately 500-2000 fibres were measured and then all values were averaged (compare Fig. 6). Each analysis was optically checked by the operator but manual editing was unnecessary in most cases.

All vessels in the micro-sections were analysed for each individual growth ring (Fig. 2, right image). For this analysis it was necessary to prepare the images. If there was more than one image per tree ring, the images had to be merged first. The last step was to cover the tylosis in the vessels with white colour allowing WinCELL to measure the vessel lumen areas correctly. All the editing steps were conducted using the software Adobe Photoshop Elements.

In case of vessel abundance multiple vessels in radial direction occurred. Each vessel was counted individually and measured as one vessel. The minimum value of the size filter was set at $600 \mu \mathrm{m}^{2}$ (diameter $=14 \mu \mathrm{m}$ ) as this proved to be the minimum size of a latewood vessel but an upper value was not set. The system frequently determined structures especially rays or large fibre cells incorrectly as vessels, which were not excluded by the filters. In such cases, the image was corrected manually.
In some cases it was difficult to distinguish an element as vessel or fibre. If it was not clear that they were classified as vessels.

Although, generally, in European ash the first earlywood vessels are much bigger than vessels formed later during the year, sometimes it is difficult to find the exact location of the boundary between earlywood and latewood. To circumnavigate this problem it was decided to select and average the $25 \%$ biggest vessels per year reflecting the majority of the earlywood vessels near the ring boundary.

\section{Results}

Some of the exposed roots of coniferous trees analysed showed an abrupt reduction of cell lumen in the earlywood from one to another year. This distinct change in cell size is attributed to a sudden exposure of the root due to an intense erosional event at the specific location. Based on former studies of anatomical changes of exposed roots it is known that permanent erosion causes a continuous lowering of the soil surface inducing a gradual reduction of cell sizes over many years, until a reduction of about $50 \%$ is reached because a large part of the root is exposed (Gärtner et al., 2001).

Fig. 3 shows the wood structure of an exposed coniferous root for the years 1983-003. From 1984 to 1994 thin cell walls and a large cell lumen are observed in the earlywood (Fig. 3). From 1996 onwards, the rings show a more stem-like wood structure, that is, cell sizes are reduced to about $50 \%$ with a continuous change of the cell dimensions at the earlywood/latewood boundary and a very distinct latewood portion. Consequently, the ring 1996 was formed after root exposure.

In comparison, Fig. 4 illustrates a typical annual ring of stem wood and annual rings of root wood in European ash. Typical differences also visible here 


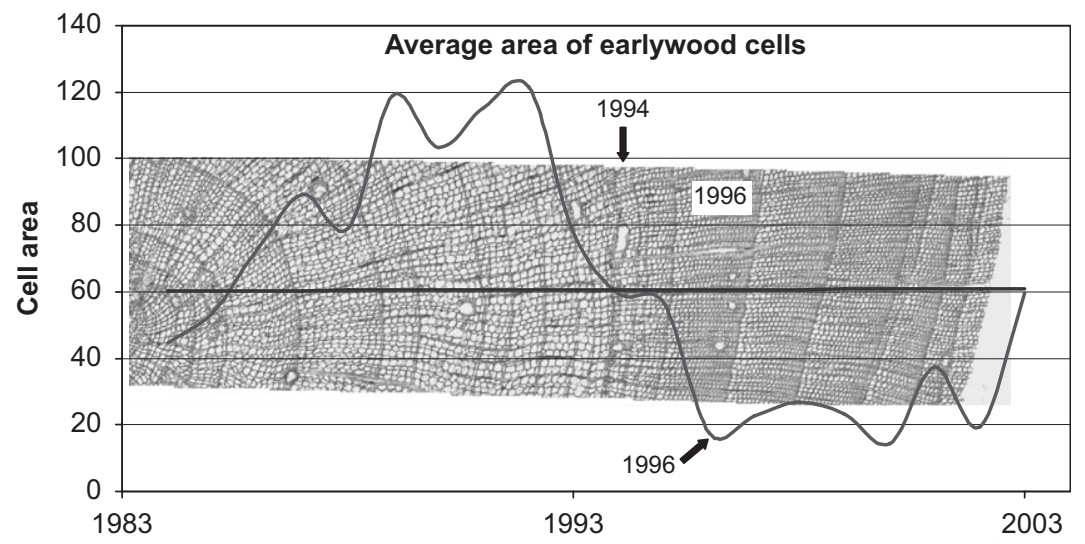

Fig. 3. Micro-section taken from a coniferous root with an overlaying plot showing changes in mean annual lumen area of earlywood cells. The arrow above indicates the year 1994 in the micro-section and the plot. The arrow below indicates the year 1996 in the plot, whereas the year 1996 in the micro-section is specified separately.

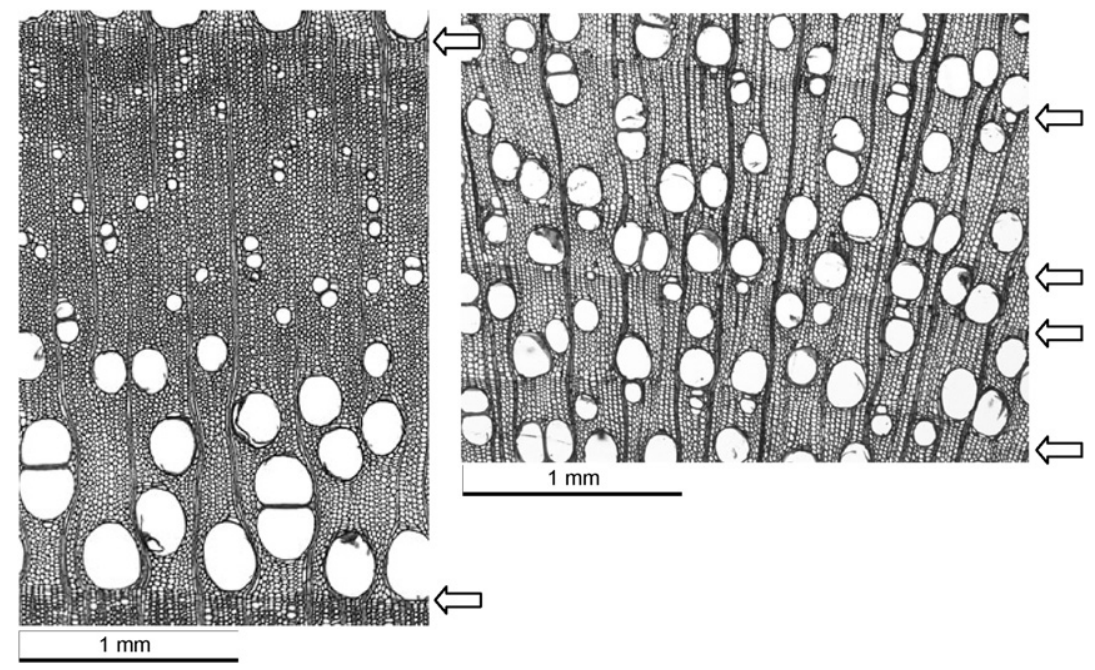

Fig. 4. Micro-sections of Fraxinus excelsior stem wood (left) and root wood (right) grown undisturbed in the soil. While in stem wood tree rings are easy to distinguish the ring boundaries (arrows) in the root wood are less distinct (stem wood: Schoch et al., 2004: http://www.woodanatomy.ch).

between stem and root wood in deciduous trees are changes in porosity, fewer cells in the annual rings of roots, their cells are wider and longer and cell walls are thinner. Vessels are generally smaller in the innermost rings and grow wider towards the bark. In ash, root wood was found to be occasionally diffuse porous to ring porous but mostly semi-ring porous, and the stem wood is always ring porous. Growth rings are usually distinct in the stem wood; in the roots they were sometimes hard to distinguish. Vessels in roots were found to be solitary and in radial pairs but occasionally in clusters and radial chains of up to four cells. In the stem, the earlywood vessels are generally packed loosely. The latewood vessels are scattered solitary, in short radial rows or in small groups.

In Fig. 5, the presented micro-section of an exposed root of an ash tree shows a change in the overall structure. The appearance of the outermost rings is darker than near the centre of the root. In the innermost part of the root the fibre cells have thin walls and big lumen areas. In addition, it is difficult to differentiate between earlywood and latewood. In the outer part of the root the cell lumen area is reduced and cell walls are thickened, thus the colour appears to be generally darker. In addition, within the annual rings the cell wall thickness increases from earlywood to latewood. Hence, the ring boundaries are distinct and earlywood and latewood is distinguishable. Furthermore, differences regarding vessel characteristics between inner- and outermost rings are also discernible. In the outermost rings, large vessels concentrate along the ring boundary in the earlywood part. Within the innermost rings the number of vessels is higher and their cell lumen area is bigger compared to the outermost part. In the innermost 


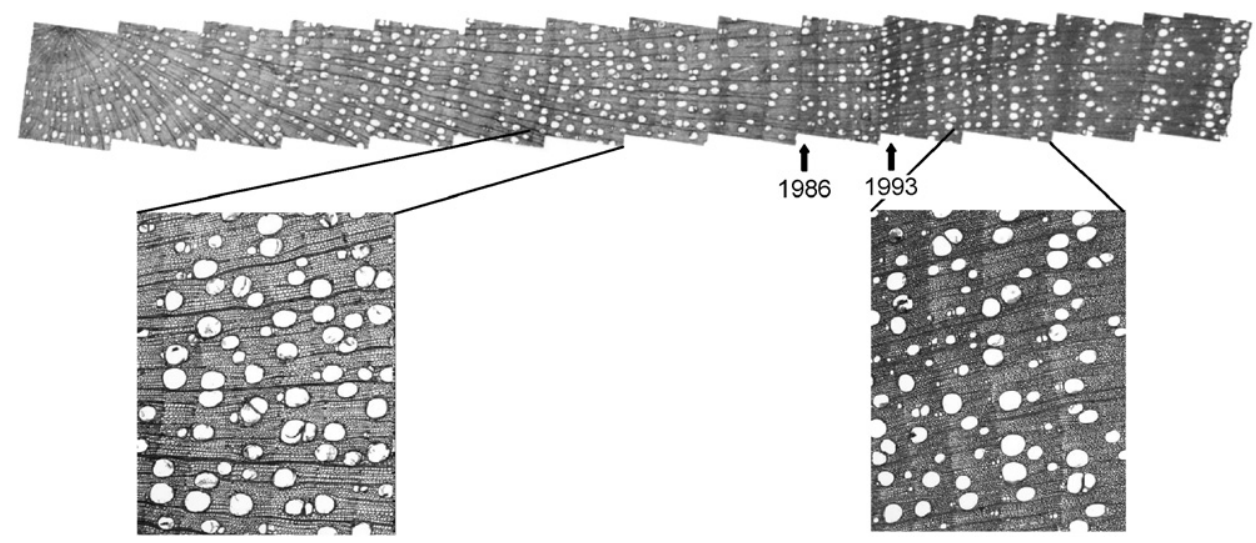

Fig. 5. Overview micro-section of an exposed ash root (see Fig. 1). Further details near the centre (left) and near the bark (right). Note that the overall structure appears darker near the bark.

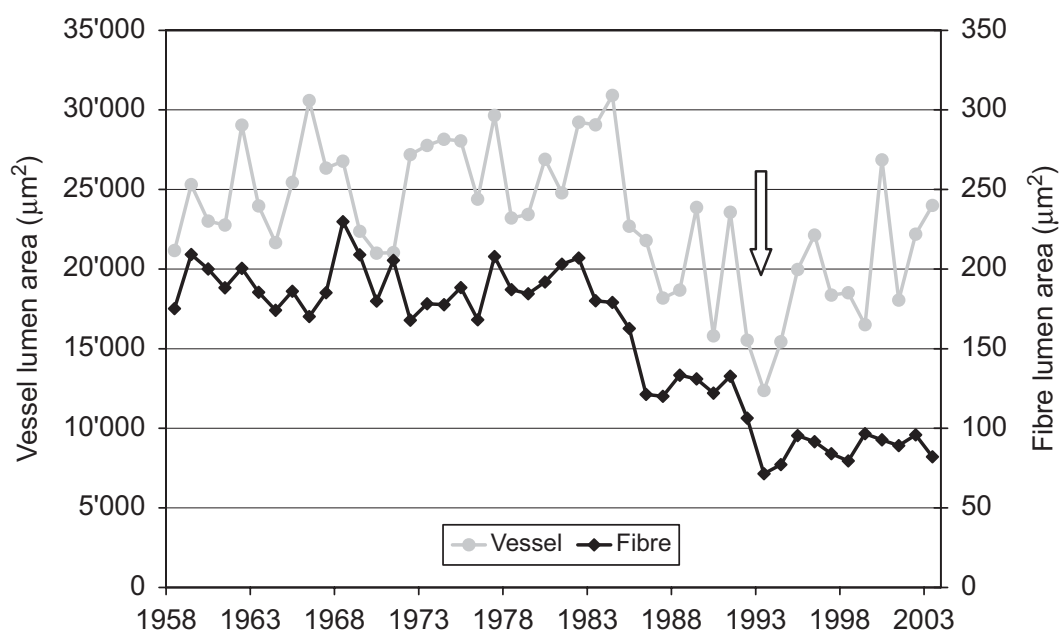

Fig. 6. Mean annual values of vessel and fibre cell lumen area measured by WinCELL. Both vessel and fibre lumen area show a distinct reduction in cell size in 1993 of approximately $50 \%$.

rings the distribution of the vessels is normally semi-ring porous but there is also a high variability from ring porous to diffuse porous. Latewood vessels mostly equal the size of earlywood vessels. Near the bark the latewood is dominated by small vessels, which are missing in the inner part of the root. The rings near the bark are typically ring porous as in stem wood.

The samples of the exposed roots show bigger vessel lumen area in the innermost rings compared to the outermost part. To investigate the observations in changing lumen size the fibres and the vessel characteristics were analysed separately. Anatomical measurements reveal similar trends with abrupt changes of the fibre lumen area after exposure (Fig. 6), a reaction comparable to that found in tracheids of coniferous roots (Fig. 3). Fig. 6 illustrates the variations in the fibre cell dimensions (black graph) showing two reductions, the first in 1986/1987 and a second in 1993. These reductions are paralleled by the values for the vessel lumen area (grey graph), which also show two reductions, one in 1987, and a second in 1993. After 1993 the reduction in fibre size is about $50 \%$, which strongly suggests that 1993 is the first ring formed after root exposure.

A second example of the same type of analysis of European ash is shown in Fig. 7. The vessel dimensions (grey line) show various minima and abrupt changes which suggests that they do not react in the same way as fibres (black line). Moreover, a general reduction in vessel dimensions is not discernible and the values in the first 6 years analysed are not remarkably higher. Two steps of reduction in fibre sizes (black line) are obvious, that is, a first minimum occurs in 1984 followed by a second in 1988. Between these dates a gradual reduction in cell size is observed. The value for $1984\left(126 \mu \mathrm{m}^{2}\right)$ is approximately $60 \%$ smaller compared to the mean value for the first period $1960-1981\left(225 \mu \mathrm{m}^{2}\right)$. The values after 1988 (average 1988-2003: $101 \mu^{2}$ ) are 50\% below 


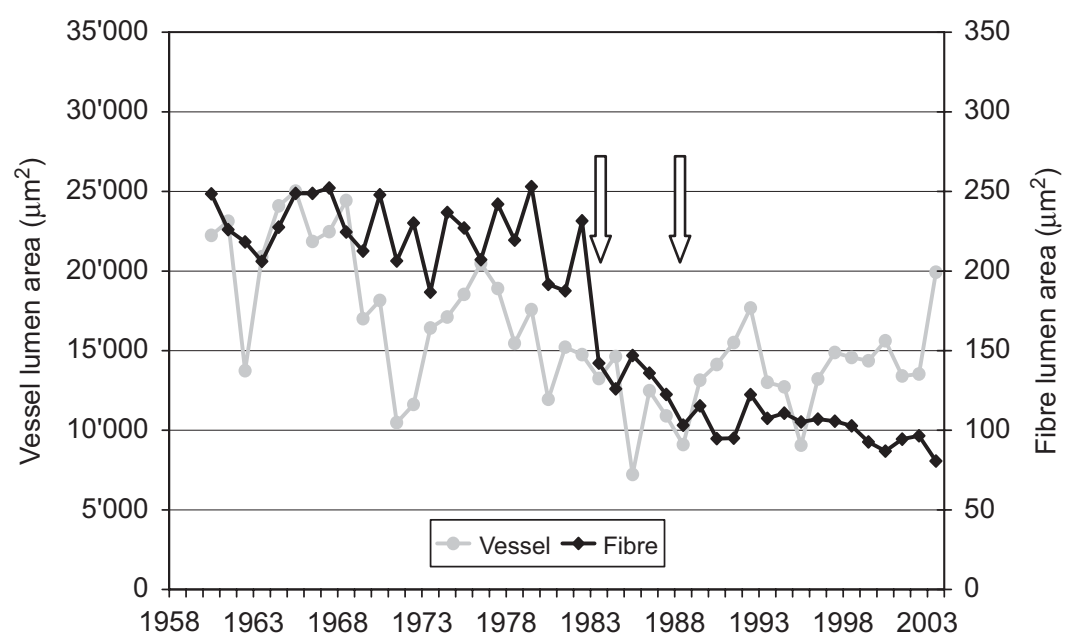

Fig. 7. Mean annual values of vessel and fibre cell lumen area measured by WinCELL (see Fig. 6). Vessel and fibre lumen areas show different reactions to exposure, only fibre size decreases clearly in 1988 by about $50 \%$.

the value of the first period $\left(225 \mu \mathrm{m}^{2}\right)$. Based on these observations we conclude that the root must have been close to the surface after 1983 and was totally exposed after 1988.

\section{Discussion}

Conifers woods, mainly consisting of tracheids, display less structural diversity than angiosperms. For example, the wood of Norway spruce consists of $95 \%$ tracheids and $5 \%$ of resin ducts and rays (Gindl and Teischinger, 2002) and thus the analysis of tracheids is the obvious way to investigate a reaction due to exposure in conifers. The anatomical structure of deciduous trees is more complex than the structure of coniferous trees and several cell types assume different physiological functions. In angiosperms, the proportions of fibres, vessels and parenchyma cells are speciesdependent, thus potential studies using wood anatomical features for geomorphological reconstructions first need to identify the elements which vary due to exposure and secondly measure and determine this reaction in each species separately. In this study, European ash has been found to only contain small proportions of parenchyma cells in roots and so we concentrated our analysis on vessels and fibres.

Considering the two graphs (Figs. 6 and 7) of exposed ash roots, both illustrate an obvious reduction in fibre cell sizes as it was found in all exposed roots of European ash analysed in this study. Only two of the roots showed a comparable reduction in vessel sizes (Fig. 6). Although the overall signal of reduction in vessel lumen area is likely to be a result of the root exposure other factors such as climate, age trend and mechanical forces also influence the vessel characteristics. Gasson (1987) stated that mean vessel size increases with tree age, hence, an age trend in vessel size can be expected. In the examples of Figs. 6 and 7(a) decreasing trend in mean vessel lumen areas is discernible. Heinrich et al. (2007) report that Fagus sylvatica and Alnus glutinosa show wood anatomical variations due to different mechanical stresses.

Various studies measured wood anatomical characters and compared them with climate data. They related wood anatomical features to a variety of ecological factors, especially those associated with moisture availability. Such a relation exists especially for vessels, which are good indicators of spring precipitation (Baas, 1973; Carlquist, 1975; Baas et al., 1983; February, 1993; Woodcock and Ignas, 1994; Sass and Eckstein, 1995; Wiemann et al., 1998; Gonzalez and Eckstein, 2003; Eilmann et al., 2006).

Although most of the cited studies mentioned above investigated stem wood only, the results seem to be at least partly applicable to root wood. However, no investigations were made concerning the relationship of wood anatomical characteristics of roots to climatic patterns, thus it is unknown which environmental factor exactly in addition to the erosional processes has influenced the annual vessel size characteristics (Figs. 6 and 7). All samples studied show a high year-to-year variability in mean vessel lumen area, which indicates that vessel characteristics in roots are likely influenced by climatic and mechanical factors as well.

The range of the year-to-year variability is smaller in mean fibre lumen area than in the mean vessel area. Exceptions are years with extremely small rings. In these years the fibres are also very small. Usually, in the following year the mean fibre lumen area recovers and returns to the previous level.

In contrast to vessels, fibres in this study show a distinct reaction consisting of a lasting reduction in lumen size from one to the next year without recovery. 
This distinct reaction occurred always in the same year as the comparable reaction in the neighbouring coniferous roots. In some instances the vessels in the ash roots reacted in the same way as the fibres; in these cases they can support the findings from the fibre size reactions (Fig. 6).

However, further investigations concerning vessel occurrence and distribution in root wood need to be conducted, especially focussing on climatic and mechanical influences including information on the microclimate. Additional studies should concentrate on the effects of slow erosional processes inducing a gradual exposure on the cell characteristics in tree roots, in contrast to a sudden exposure due to one abrupt erosion event as examined in the current study.

\section{Conclusion}

This study shows, for the first time, that it is possible to determine wood anatomical reactions in roots of European ash due to exposure. These reactions within the xylem of roots can be used as a new dating tool to reconstruct the exact year of exposure and hence of erosional processes in vegetation zones dominated by angiosperms. Due to the complex and specialised structure of angiosperm wood it potentially holds more information than coniferous wood and thus has the potential to deliver further details on the processes of root exposure and the different erosion processes (continuous or discontinuous erosion).

Nevertheless, further analyses need to be conducted to define more comprehensively the specific wood structural anomalies occurring during and after angiosperm root exposure.

\section{Acknowledgements}

The authors wish to thank the Federal Office for the Environment (FOEN) for funding the project. Furthermore we wish to thank Christian Rickli, Hansueli Bucher, Tobias Meyer and Raphael Holland for their support in the field.

\section{References}

Baas, P., 1973. The wood anatomical range in Ilex (Aquifoliaceae) and its ecological and phylogenetic significance. Blumea 21, 193-258.

Baas, P., Werker, E., Fahn, A., 1983. Some ecological trends in vessel characters. IAWA Bulletin 4 (2-3), 141-159.

Carlquist, S., 1975. Ecological Strategies of Xylem Evolution. University of California Press, Berkeley, 259pp.
Eilmann, B., Weber, P., Rigling, A., Eckstein, D., 2006. Growth reactions of Pinus sylvestris L. and Quercus pubescens Willd. to drought years at a xeric site in Valais, Switzerland. Dendrochronologia 23, 121-132.

Fayle, D.C.F., 1968. Radial Growth in Tree Roots Distribution, Timing, Anatomy. Faculty of Forestry. University of Toronto, Technical Report No. 9, 183pp.

February, E., 1993. Sensitivity of xylem vessel size and frequency to rainfall and temperature: implications for palaeontology. Paleontological Africa 30, 91-95.

Gärtner, H., 2003. Holzanatomische Analyse diagnostischer Merkmale einer Freilegungsreaktion in Jahrringen von Koniferenwurzeln zur Rekonstruktion geomorphologischer Prozesse. Dissertationes Botanicae 378, 1-118.

Gärtner, H., 2007. Tree roots - methodological review and new development in dating and quantifying erosive processes. Geomorphology 86 (3-4), 243-251.

Gärtner, H., Schweingruber, F.H., Dikau, R., 2001. Determination of erosion rates by analyzing structural changes in the growth pattern of exposed roots. Dendrochronologia 19, 81-91.

Gasson, P., 1987. Some implications of anatomical variations in the wood of pedunculate oak (Quercus robur L.), including comparisons with common beech (Fagus sylvatica L.). IAWA Bulletin 8 (2), 149-166.

Gindl, W., Teischinger, A., 2002. Axial compression strength of Norway spruce related to structural variability and lignin content. Composites Part A 33, 1623-1628.

Gonzalez, I.G., Eckstein, D., 2003. Climatic signal of earlywood vessels of oak on a maritime site. Tree Physiology 23, 497-504.

Heinrich, I., Gärtner, H., Monbaron, M., 2007. Tension wood formed in Fagus sylvatica and Alnus glutinosa after simulated mass movement events. IAWA Journal 28 (1), 39-48.

IPCC, Climate Change 2001. The Scientific Basis: A Contribution of Working Group I to the Second Assessment Report of the Intergovernmental Panel of Climate Change. Cambridge University Press, 881pp.

Morneau, C., Payette, S., 1998. A dendroecological method to evaluate past caribou (Rangifer tarandus L.) activity. Ecoscience 5 (1), 64-76.

PLANAT, 2005. Strategie Naturgefahren Schweiz Synthesebericht. 〈http://www.planat.ch/ressources/planat_product_ de_543.pdf $\rangle$.

Sass, U., Eckstein, D., 1995. The variability of vessel size in beech (Fagus sylvatica L.) and its ecophysiological interpretation. Trees 9, 247-252.

Schoch, W., Heller, I., Schweingruber, F.H., Kienast, F., 2004. Wood anatomy of central European Species (Online version: 〈www.woodanatomy.ch〉).

Schumm, S.A., 2003. The Fluvial System. The Blackburn Press, Caldwell, USA, 338pp.

Schweingruber, F.H., 1978. Mikroskopische Holzanatomie. Birmensdorf, Eidgenössische Anstalt für das forstliche Versuchswesen, 226pp.

Wasser, B., Frehner, M., 1996. Wegleitung Minimale Pflegemassnahmen für Wälder mit Schutzfunktion. Vollzug Umwelt. Bundesamt für Umwelt, Wald und Landschaft. 
Wiemann, M.C., Wheeler, E.A., Manchester, S.R., Portier, K.M., 1998. Dicotyledonous wood anatomical characters as predictors of climate. Palaeogeography, Palaeoclimatology, Palaeoecology 139, 83-100.
Woodcock, D.W., Ignas, C.M., 1994. Prevalence of wood characters in eastern North America: what characters are most promising for interpreting climates from fossil wood? American Journal of Botany 81, 1243-1251. 